\title{
Quantification of flavonoids by UPLC-MS and its antibacterial activity from Brassica oleracea var. Capitata L.
}

\author{
Satish A., Farha Syeda S. and Urooj Asna* \\ Department of Studies in Food Science and Nutrition, University of Mysore, Manasagangothri, Mysuru -570 006, \\ Karnataka, India.
}

Publication history: Received on 19 September 2018; revised on 05 October 2018; accepted on 10 October 2018

Article DOI: https://doi.org/10.30574/gscbps.2018.5.1.0105

\begin{abstract}
Foodborne diseases remain considerable topic of concern and food safety is an important health, social and economical issue. Food borne illnesses caused by the contamination of microbes increases the concerns to find alternate sources which are safe to human health and environment. This study is the first attempt designed to determine the flavonoid content by UPLC-MS in the Indian variety of Brassica oleracea var. capitata L.(organic white cabbage) cultivated in Mysuru region and their potent antibacterial property against food borne pathogens. In the results of the present study, different flavonoids such as genistein > kaempherol > naringenin and catechin was observed which possess antibacterial activity. The antibacterial results showed that the flavonoids and there derivatives have potent antibacterial activity against the gram positive Staphylococcus aureus and the gram negative E. coli. Hence it can be concluded from the study that potential for developing antibacterial from organic white cabbage appears rewarding for the development of phytomedicine to act against microbes.
\end{abstract}

Keywords: Phytochemicals; Pathogenic bacteria; Cabbage; UPLC-MS

\section{Introduction}

Consumption of contaminated food with pathogenic bacteria and their metabolites results in food borne diseases. Controlling the food borne pathogens by identifying and evaluating effective antibacterial agents from natural products and assure safe food supply is the major global concern [1]. Cabbage has widespread use in traditional medicine due to their antioxidant, anti-inflammatory and antibacterial properties [2]. Studies have reported that use of synthetic food preservatives use may lead to negative health consequences. Hence there is an increased interest in the possible healthpromoting effects of phenolic phytochemicals including flavonoids in vegetables [3]. Researchers have shown that naturally occurring bioactive compounds from plant origin have greater antimicrobial activity than synthetic compound due to their adverse effects [4].

Flavonoids denotes the secondary metabolite class in cruciferous vegetables. Their potential as natural antioxidants has raised significant interest. The impacts of flavonoids on the human body after consumption as well as their effect as pharmaceutical supplements are therefore under exploration [5]. Their numerous physiological functions make them a promising tool for breeding purposes. General methods for the analysis of flavonoid are well established, though new compounds are still being identified. However, differences in environmental circumstances of the studies and analytical methods impede comparability of quantification results. Hence, the present study is the first attempt designed to determine the flavonoid content by UPLC-MS in the Indian variety of Brassica oleracea var. capitata L. (organic white cabbage) cultivated in Mysuru region and their potent antimicrobial property against food borne bacteria in-order to explore their application as pharmaceutical supplements.

\footnotetext{
${ }^{*}$ Corresponding author

E-mail address: asnaurooj@foodsci.uni-mysore.ac.in
} 


\section{Material and methods}

\subsection{Sample collection}

Organic white cabbages were harvested and collected from Hasiru organic farm, Mysuru district in the month of April 2017. They were cleaned immediately and freeze dried. The dried samples were kept in deep freezer $\left(-20^{\circ} \mathrm{C}\right)$ and used for further analysis.

\subsection{Chemicals}

Standards viz, genistein, kaempherol, naringenin and catechin, were purchased from Sigma-Aldrich Chemicals Co. (India). All other chemicals and solvents used were of analytical grade.

\subsection{Preparation of extract}

The freeze dried sample was extracted as per the procedure described by Renuka Devi and Thangam [6], with slight modification. Lyophilized sample was macerated with $80 \%$ methanol ( $4 \mathrm{~mL} / \mathrm{g}$ of weight) and extracted for $18 \mathrm{hrs}$ before filtration. The plant material was re-extracted twice with cold $80 \%$ methanol for 4 hrs each time with frequent swirling. The filtrates were combined, concentrated by drying in oven and it was used further for the analysis.

\subsection{Test organisms}

Bacillus subtilis (MTCC 121), Staphylococcus aureus (MTCC 7443), Escherichia coli (MTCC 7410), Salmonella typhimurium (MTCC 733) were used in this study.

\subsection{Detection and quantification of bioactive components by UPLC/MS}

LC-MS analysis was performed using a Waters (Acuity UPLC, USA) system coupled to a Q-TOF (Quadrupole time of flight) mass spectrometer (Synapt G2, USA) equipped with an electrospray ionization (negative mode) source that was used at an ion source temperature of $100{ }^{\circ} \mathrm{C}$. The detection and quantification by UPLC/MS method was followed by our previously published method [7].The test sample was dissolved in $80 \%$ methanol and $0.2 \mu \mathrm{L}$ of sample was injected on acquity UPLC BEH $\mathrm{C}_{18}$ column $(1.7 \mu \mathrm{m} 1.0 \times 50 \mathrm{~mm})$ at a flow rate of $0.3 \mathrm{ml} / \mathrm{min}$. Solvent A consisted of $0.1 \%$ Formic acid in water and solvent B consisted of acetonitrile solvent. Gradient program was used for elution: Initially, Solvent B concentration was $2 \%$ and increased to $98 \%$ at 4 min and maintained up to 6 min and finally at 8 min B concentration was $2 \%$. The mass spectrometer was operated in $\left[\mathrm{M}^{+} \mathrm{H}\right]$ Positive ion mode. Capillary voltage was set at $2.5 \mathrm{kv}$ and the cone voltage was optimized for each of the compounds. Molecular species were identified within the mass to charge ratio (m/z) range 50 to 1500 . Data acquisition was carried out by Mass Lynx Software (Version: 4.1).

\subsection{Antibacterial assay}

The antibacterial activity of organic white cabbage was determined by disc diffusion method [8] against both Grampositive (Staphylococcus aureus and Bacillus subtilis) and Gram-negative (Escherichia coli and Salmonella typhimurium) bacteria. Each sterile disc $(6 \mathrm{~mm})$ was loaded with $25 \mu \mathrm{l}$ of organic white cabbage $\left(10,25\right.$ and $50 \mu \mathrm{g}$ disc $\left.{ }^{-1}\right)$ and placed equidistantly on nutrient agar plates seeded with test bacteria $\left(1.5 \times 10^{8} \mathrm{CFU} \mathrm{mL}^{-1}\right)$. Streptomycin $\left(25 \mu \mathrm{g}\right.$ disc $\left.{ }^{-1}\right)$ and $80 \%$ methanol served as positive and negative controls, respectively. The plates were sealed using parafilm and incubated at $37 \pm 2{ }^{\circ} \mathrm{C}$ for $24 \mathrm{~h}$ and zone of inhibition was measured.

\section{Results}

The present study UPLC-MS profile highlighted the presence of flavonoids where each compound was identified mainly based on the mass spectrometric data and by using corresponding standards the comparison was made. Each compound was analyzed on mass spectrometry under positive modes. The chromatograms and mass spectra of organic white cabbage are illustrated in Figure 1. 

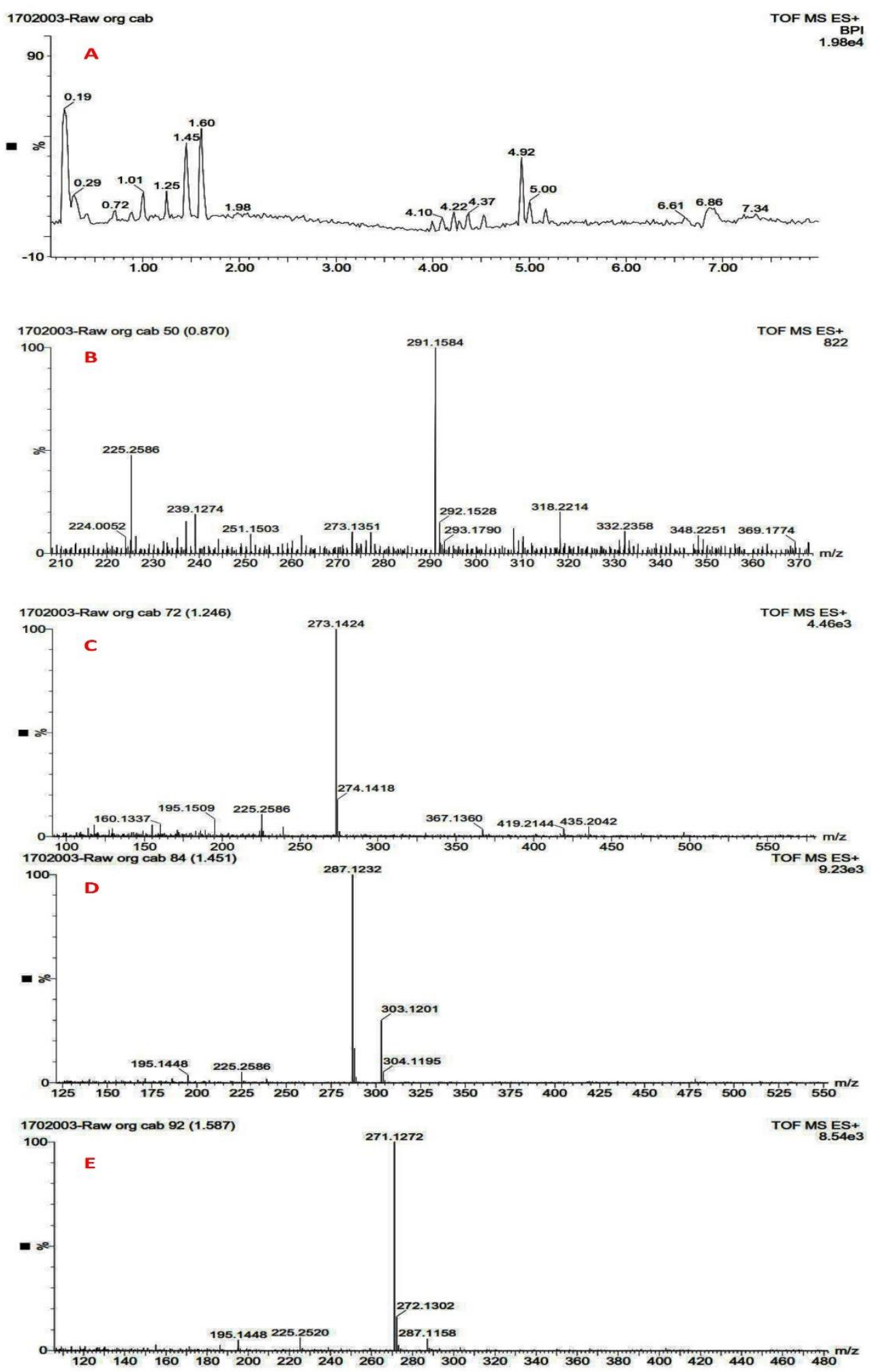

Figure 1 The chromatogram and mass spectra of organic white cabbage by UPLC/MS. (A) Chromatogram of Organic white cabbage (B) Mass spectra of Catechin (C) Naringenin (D) Kaempherol and (E) Genistein.

The retention time, molecular mas and quantity are summarized in Table 1. Among these, genistein (1.632 $\left.\mathrm{mg} \mathrm{g}^{-1}\right)$ content was the highest followed by kaempherol $\left(1.229 \mathrm{mg} \mathrm{g}^{-1}\right)$, naringenin $\left(0.585 \mathrm{mg} \mathrm{g}^{-1}\right)$, catechin $\left(0.168 \mathrm{mg} \mathrm{g}^{-1}\right)$ on wet basis. 
Satish et al. / GSC Biological and Pharmaceutical Sciences 2018, 05(01), 109-114

Table 1 Identification and quantification of flavonoid content in organic white cabbage estimated by UPLC-MS

\begin{tabular}{llllll}
\hline $\begin{array}{l}\text { Cruciferous vegetable } \\
\text { extract } \\
\text { methanol) }\end{array}$ & $\mathbf{( 8 0 \%}$ & Catechin & Naringenin & Kaempherol & Genistein \\
\hline & $\mathrm{t}_{\mathrm{R}}(\mathrm{min})$ & 0.87 & 1.24 & 1.45 & 1.58 \\
$\begin{array}{l}\text { Organic } \\
\text { white }\end{array}$ & {$\left[\mathrm{M}^{+} \mathrm{H}\right]^{+}$} & 291.18 & 273.17 & 287.15 & 271.15 \\
cabbage & $\mathrm{mg} / \mathrm{gm}$ & 0.168 & 0.585 & 1.229 & 1.632 \\
\hline \multicolumn{5}{c}{} & $\mathrm{t}_{\mathrm{R}}(\mathrm{min}):$ Retention time; $\left[\mathrm{M}^{+} \mathrm{H}\right]^{+}:$Molecular weight; $\mathrm{mg} /$ gm: expressed on wet basis
\end{tabular}

The antibacterial activities expressed as inhibition zone diameters of the organic white cabbage at different concentrations $\left(10,25\right.$ and $50 \mu$ disc $\left.^{-1}\right)$ against the E. coli, Salmonella typhi, Bacillus subtilis and Staphylococcus aureus are in (Figure 2 and Table 2). It was observed that no antibacterial activity was found at $10 \mu \mathrm{g}$ disc ${ }^{-1}$. It was noted that

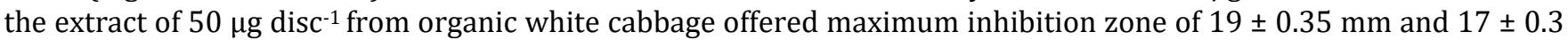
$\mathrm{mm}$ against the gram positive Staphylococcus aureus and the gram negative E. coli respectively. The extract concentration at $50 \mu \mathrm{g} \mathrm{disc}{ }^{-1}$ and streptomycin at $25 \mu \mathrm{g} \mathrm{disc} \mathrm{d}^{-1}$ (positive control) had comparable antibacterial activity.

Table 2 Inhibitory activity of organic white cabbage against different pathogenic bacteria

\begin{tabular}{|c|c|c|c|c|c|}
\hline \multirow[t]{2}{*}{ Test organisms } & \multicolumn{5}{|c|}{ Zone of inhibition (mm) } \\
\hline & $10 \mathrm{mg} / \mathrm{disc}$ & $25 \mathrm{mg} / \mathrm{disc}$ & $50 \mathrm{mg} / \mathrm{disc}$ & $\begin{array}{l}\text { Positive } \\
\text { control }\end{array}$ & $\begin{array}{l}\text { Negative } \\
\text { control }\end{array}$ \\
\hline E. coli & 0.0 & $12 \pm 0.4$ & $17 \pm 0.3$ & $17 \pm 0.32$ & 0.0 \\
\hline Salmonella typhi & 0.0 & $12 \pm 0.23$ & $14 \pm 0.32$ & $15 \pm 0.6$ & 0.0 \\
\hline Bacillus subtilis & 0.0 & $10 \pm 0.6$ & $12 \pm 0.45$ & $12 \pm 0.62$ & 0.0 \\
\hline $\begin{array}{l}\text { Staphylococcus } \\
\text { aureus }\end{array}$ & 0.0 & $13 \pm 0.42$ & $19 \pm 0.35$ & $16 \pm 0.2$ & 0.0 \\
\hline
\end{tabular}
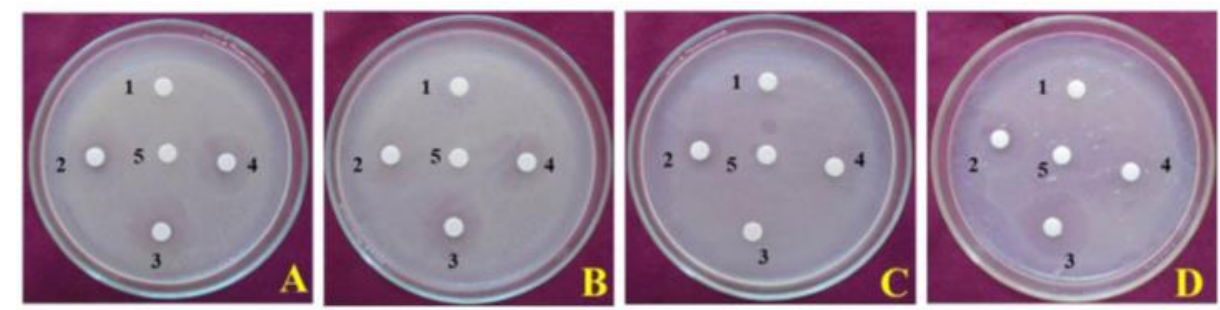

Figure 2 Inhibitory activity of organic white cabbage against test pathogens by disc diffusion method. A-E. coli; B- $S$. typhi; C- B. subtilis; D- S. aureus; $1-10 \mathrm{mg} / \mathrm{ml} ; 2-25 \mathrm{mg} / \mathrm{ml} ; 3-50 \mathrm{mg} / \mathrm{ml}$; 4- Positive control; 5-Negative control

\section{Discussion}

Flavonoids are ubiquitous in photosynthesizing cells and are commonly found in fruit, vegetables, nuts, seeds, tea, stems, flowers, honey, wine and propolis. For centuries, to treat human diseases, preparations containing these compounds (the principal physiologically active constituents) have been used [9].The present experiment analyzed phytochemicals in organic white cabbage and has identified the presence of different flavonoids such as genistein, kaempherol, naringenin and catechin which have been attributed to its potent antibacterial activity. Flavonoids act as antimicrobial agents in different ways including direct antibacterial activity, combined effect with antibiotics and virulence suppression [10]. Flavonoids such as kaempherol and quercetin have antibacterial activities against Propionibacterium, inhibitory effects of apigenin against S. typhi, Proteus mirabilis and P. aeruginosa [11] and selective 
toxicity of apigenin and luteolin against $S$. aureus including the methicillin-resistance $S$. aureus (MRSA) and methicillinsensitive $S$. aureus strains (MSSA) [12].

It has been postulated that cell membrane of gram negative bacteria contains many condensed fat layers compared with gram positive bacteria and there is difficulty in penetration of chemicals, antibiotics or antiseptics. To overcome this, flavonoid extract were used which contains hydroxyl group, reacting with the phospholipids of bacterial cell wall. This leads to the distraction of cell membrane and increase the permeability of cell membranes of antibacterial compounds by denaturing the cell protein [13].

Our previous study has analyzed the presence of glucosinolates which includes allyl isothiocyanate, iberin and indole3-carboxyaldehyde in higher amounts which are rich in sulphur containing compounds [14]. It was reported that sulfhydryl groups easily bind with specific enzymes essential for microbial growth and survival. This binding restricts the enzymes activity causing reduction in the cellular levels of important thiol groups, leading to the formation of oxygen and other free radicals [15], which reduces the viability of bacterial cells. Studies have shown that, the quantity of kaempherol varied from 0 to $1.2 \mathrm{mg} / 100 \mathrm{~g}$ in Chinese cabbage, white cabbage and red cabbage [16]. In our study the content of kaempherol and quercetin varied slightly. Hence, it can be concluded that the difference in the production of secondary metabolites are affected quantitatively as well as qualitatively by a range of environmental factors, including temperature, light intensity, relative humidity, soil type, irrigation water quality and day length, as well as by genetic factors.

\section{Conclusion}

It could be concluded from the present study that different agro-climatic conditions influence the phytonutrient content, composition and antibacterial activity of the organic white cabbage. Hence, from the results obtained appears that potential for developing antimicrobials from cruciferous vegetables appears rewarding as it will lead to the development of phytomedicine to act against microbes. Plant-based antimicrobials can serve the purpose of synthetic antimicrobials have enormous therapeutic activity. Therefore, further in-depth studies to develop antimicrobials from cruciferous vegetables are needed.

\section{Compliance with ethical standards}

\section{Acknowledgments}

With deep gratitude, authors are grateful to the Indian Council of Medical Research New Delhi, Directorate of Minorities, Karnataka and UGC-DRS II for providing financial assistance. We heartily thank to Dr. Murali and Mr. Mahendra, DOS in Botany, University of Mysore for carrying out anti-microbial studies. We are also grateful to Institution of Excellence (IOE) and University with Potential for Excellence (UPE), University of Mysore, Mysuru for providing instrumentation facilities.

\section{Disclosure of conflict of interest}

The authors declare that there is no conflict of interest.

\section{References}

[1] Sibi G, Shukla A, Dhananjaya K, Ravikumar KR and Mallesha H. (2013). In vitro antibacterial activities of Broccoli (Brassica oleracea L. var italica) against food borne bacteria. Journal of Applied Pharmaceutical Science, 3(5), 1.

[2] Rokayya S, Li CJ, Zhao Y, Li Y and Sun CH. (2013). Cabbage (Brassica oleracea L. var. capitata) phytochemicals with antioxidant and anti-inflammatory potential. Asian Pacific Journal of Cancer Prevention, 14(11), 6657-6662.

[3] Kim DO, Padilla-Zakour OI and Griffiths PD. (2004). Flavonoids and antioxidant capacity of various cabbage genotypes at juvenile stage. Journal of Food Science, 69(9), C685-C689.

[4] Aljamali NM. (2013). Study effect of medical plant extracts in comparison with antibiotic against bacteria. International journal of science and innovative research, 2, 843-845.

[5] Nijveldt RJ, Van Nood ELS, Van Hoorn DE, Boelens PG, Van Norren K and Van Leeuwen PA. (2001). Flavonoids: a review of probable mechanisms of action and potential applications. The American journal of clinical nutrition, 74(4), 418-425. 
[6] Devi JR and Thangam EB. (2010). Extraction and separation of glucosinolates from Brassica oleraceae var Rubra. Advances in Biological Research, 4(6), 309-313.

[7] Anandan S, Kotebagilu NP, Shivanna LM and Urooj A. (2017). Inhibitory potency of C-glycosyl flavonoids from morus sp. on advanced glycation end products. Journal of Biologically Active Products from Nature, 7(5), 391400 .

[8] Mahendra C, Murali M, Manasa G, Ponnamma P, Abhilash MR, Lakshmeesha TR and Sudarshana MS. (2017). Antibacterial and antimitotic potential of bio-fabricated zinc oxide nanoparticles of Cochlospermum religiosum (L.). Microbial pathogenesis, 110, 620-629.

[9] Cushnie TT and Lamb AJ. (2005). Antimicrobial activity of flavonoids. International journal of antimicrobial agents, 26(5), 343-356.

[10] Cushnie TT and Lamb AJ. (2011). Recent advances in understanding the antibacterial properties of flavonoids. International journal of antimicrobial agents, 38(2), 99-107.

[11] Tofighi Z, Molazem M, Doostdar B, Taban P, Shahverdi AR, Samadi N and Yassa N. (2015). Antimicrobial activities of three medicinal plants and investigation of flavonoids of tripleurospermum disciforme. Iranian journal of pharmaceutical research, IJPR, 14(1), 225.

[12] Sato Y, Suzaki S, Nishikawa T, Kihara M, Shibata H and Higuti T. (2000). Phytochemical flavones isolated from Scutellaria barbata and antibacterial activity against methicillin-resistant Staphylococcus aureus. Journal of ethnopharmacology, 72(3), 483-488.

[13] Zearah SA and Al-Kanany GF. (2014). Antimicrobial activity of flavonoid compound isolated from Inula greaveolens l. plant on selected pathogenic bacteria. Basrah Journal of Veterinary Research.13 (1), 1-10.

[14] Anandan S, Syeda FS, Mahadeva MJ and Urooj A. (2018). Glucosinolates and antioxidant properties of Brassica oleracea var. capitata L. Food Science and Nutrition Technology, 3(3), 000152.

[15] Wilson AE, Bergaentzle M, Bindler F, Marchioni E, Lintz A and Ennahar S. (2013). In vitro efficacies of various isothiocyanates from cruciferous vegetables as antimicrobial agents against foodborne pathogens and spoilage bacteria. Food Control, 30(1), 318-324.

[16] Kim DO, Padilla-Zakour OI and Griffiths PD. (2004). Flavonoids and antioxidant capacity of various cabbage genotypes at juvenile stage. Journal of Food Science, 69(9), C685-C689.

\section{How to cite this article}

Satish A, Farha Syeda S and Urooj A. (2018). Quantification of flavonoids by UPLC-MS and its antibacterial activity from Brassica oleracea var. Capitata L. GSC Biological and Pharmaceutical Sciences, 5(1), 109-114. 